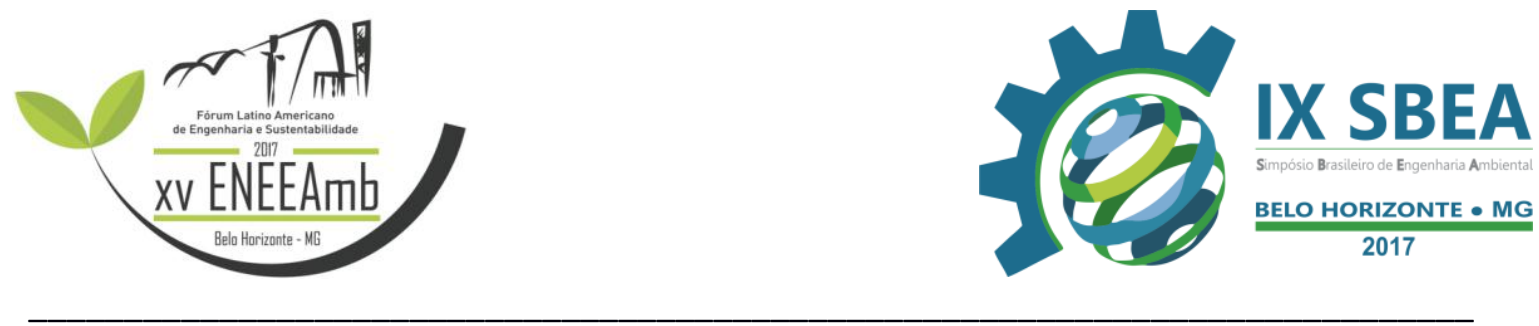

ÁREA TEMÁTICA: PLANEJAMENTO, ORDENAMENTO E GESTÃo INTEGRADA

\title{
ANÁLISE QUALITATIVA DA GESTÃO DE RESÍDUOS SÓLIDOS NO MUNICÍPIO DE PARAGOMINAS-PA
}

\author{
Lorena Saraiva Viana - lorenaengamb20@gmail.com \\ Universidade do Estado do Pará \\ Lucimar Costa Pereira-lu.costa0708@gmail.com \\ Universidade do Estado do Pará \\ Maria Renata da Rocha Xavier - renatarochax@ hotamail.com \\ Universidade do Estado do Pará \\ Maycon Viana Balbino - maycon.lbino@ hotmail.com \\ Universidade do Estado do Pará \\ Nayara do Socorro Nascimento Farias - nayarafarias@ outlook.com \\ Universidade do Estado do Pará
}

\section{RESUMO}

A presença de uma quantidade significativa de resíduos no meio ambiente representa grandes ameaças na qualidade do mesmo, necessitando dessa forma de uma gestão adequada de resíduos, que priorize a não geração, minimização e o reaproveitamento dos resíduos, com o objetivo de impedir os efeitos adversos sobre o meio ambiente.

O presente trabalho objetivou realizar uma análise qualitativa sistemática da gestão dos resíduos sólidos no município de Paragominas-Pará com base na política nacional de Resíduos Sólidos, no plano estadual de gestão integrada de resíduos sólidos e no plano diretor de urbanismo do município. 

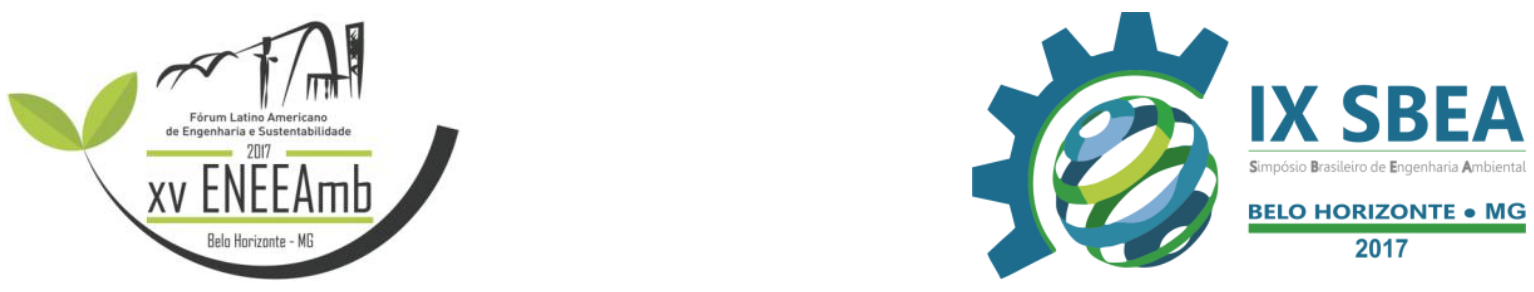

A prática de trabalho adotada neste estudo, foi através de entrevistas com atores sociais ligados a gestão de resíduos sólidos no município de Paragominas, complementada por uma avaliação crítica das respostas dos entrevistados com base no conteúdo das legislações referentes a gestão de resíduos. A gestão integrada de resíduos sólidos não é realizada no município de Paragominas, e é comumente confundida com o gerenciamento de resíduos sólidos. O mesmo ainda não apresenta a praticidade da coleta seletiva. Entretanto, já obteve a aprovação de um programa de coleta seletiva pelo Governo Federal. O município de Paragominas conta atualmente com duas cooperativas de resíduos sólidos, uma de resíduos secos e outra de resíduos orgânicos no condomínio. A partir da análise efetivada por meio de entrevistas com atores sociais ligados à gestão de resíduos sólidos no município de Paragominas e no estudo das Legislações pertinentes à gestão integrada de resíduos sólidos, verificou-se que o município desempenha uma gestão que não está em consonância total com a Política Nacional de Resíduos Sólidos.

Palavras-Chave: Cooperativa, Municípios, Legislações.

\section{INTRODUÇÃO}

Com o avanço tecnológico e econômico, houve o aumento na produção de bens de consumo duráveis e não-duráveis. Com isso, surgiram produtos inovadores, porém de baixa vida útil, o que contribuiu para o aumento da exploração de recursos naturais (PEREIRA, 2006). Esta constante utilização dos recursos contribui para a formação de uma quantidade significativa de resíduos sólidos.

O termo resíduos sólidos é definido pela NBR ABNT 10.004:2004 como "resíduos nos estados sólido e semissólido, que resultam de atividades de origem industrial, doméstica, hospitalar, comercial, agrícola, de serviços e de varrição" (ABNT, 2004).

Nesta classificação, destacamos os resíduos urbanos como um problema mundial decorrente da alteração nos padrões de consumo. A presença de tais materiais no meio ambiente representa grandes ameaças na qualidade do mesmo, necessitando dessa forma de uma gestão adequada de resíduos.

IX Simpósio Brasileiro de Engenharia Ambiental, XV Encontro Nacional de Estudantes de Engenharia Ambiental e III

Fórum Latino Americano de Engenharia e Sustentabilidade 

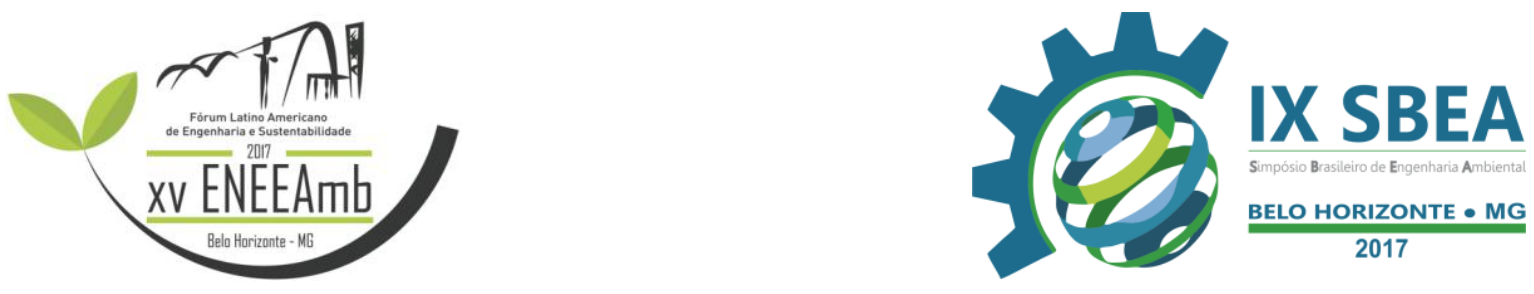

Neste contexto, é verificável que as questões ambientais tornam a gestão de resíduos um procedimento de importância significativa para a proteção e garantia da qualidade da saúde humana e do meio ambiente. A gestão integrada de resíduos deve dar prioridade para não geração, a minimização da geração e o reaproveitamento dos resíduos, com o objetivo de impedir os efeitos adversos sobre o meio ambiente (SCHNEIDER, 2009).

A Política Nacional de Resíduos Sólidos (PNRS), instituída pela Lei n 12.305:2010, no Art.3, inc. XI, conceitua gestão integrada de resíduos sólidos como um "conjunto de ações voltadas para a busca de soluções para os resíduos sólidos, de forma a considerar as dimensões política, econômica, ambiental, cultural e social, com controle social e sob a premissa do desenvolvimento sustentável".

A Gestão Integrada de Resíduos Sólidos leva em consideração uma aberta participação e intercooperação de todos aqueles que de certa forma representam a sociedade de todos os setores como exemplo: governo central; governo local; setor formal; setor privado; ONGs; setor informal; catadores; comunidade; todos geradores e responsáveis pelos resíduos (MESQUITA, 2007).

A gestão dos Resíduos Sólidos Urbanos (RSU) apresenta-se atualmente como um problema diário para os Órgãos públicos, no que se refere aos aspectos ambiental, econômico e social, o que não pode ser mais visto como despesa, mas algo necessário do passivo ambiental ao qual afeta diretamente ao que seria a qualidade de vida das pessoas (GÓES, 2011).

Segundo a Constituição Federal de 1988 a proteção ao meio ambiente e o combate a qualquer tipo de poluição é expressamente apresentada no Art. 23 como de capacidade comum de todos os órgãos federados (União, Estados, Distrito Federal e municípios) (BRASIL, 1988). Desta forma, os Estados poderão atuar por meio de secretarias Estatuais de Meio Ambiente e União, por meio do Ministério das cidades e Ministério do meio Ambiente, para combater a poluição dos resíduos sólidos.

A PNRS ainda dispõe sobre seus princípios, objetivos e instrumentos, que a responsabilidade pela gestão integrada e diretrizes sobre os resíduos sólidos em cada territórios é de responsabilidade do Distrito Federal e dos Municípios, bem como a obrigação dos geradores em gerenciar os resíduos (BRASIL, 2010).

Neste contexto o presente trabalho objetivou realizar uma análise qualitativa sistemática da gestão dos resíduos sólidos no município de Paragominas-Pará com base na política nacional 

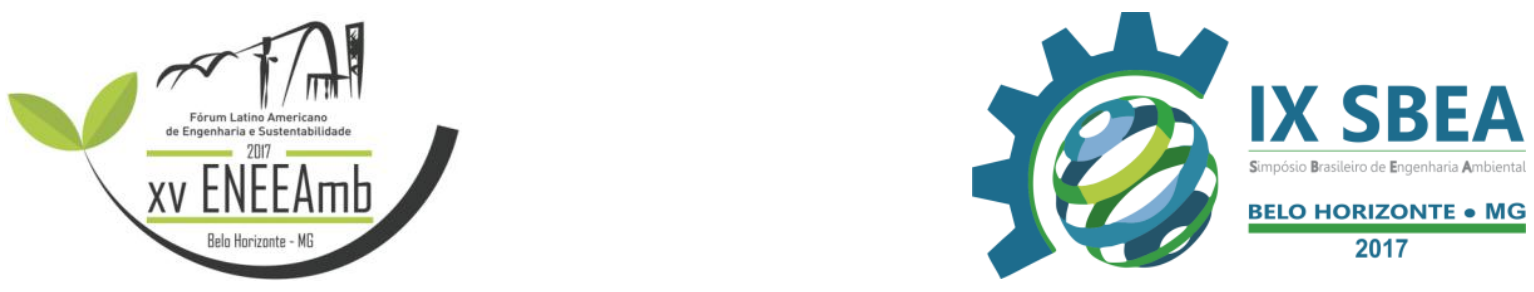

de Resíduos Sólidos (PNRS Lei n. 12.305:2010) e no plano diretor de urbanismo do município (PARAGOMINAS, 2006).

\section{METODOLOGIA}

A metodologia utilizada neste trabalho foi do tipo observativa, sistemática, direta, in situ, com aplicação de um formulário aberto contendo questões referentes a gestão de resíduos sólidos do município de Paragominas-PA (quadros 1, 2 e 3). Os formulários foram aplicados a três atores sociais ligados de forma direta e indireta à gestão de resíduos, sendo eles um membro da secretaria de limpeza (entrevistado A), membro de uma cooperativa de resíduos sólidos, denominada COOPERCAMARI e uma das responsáveis pelo aterro controlado do município.

\section{RESULTADOS E DISCUSSÃO}

\subsection{POLÍTICA NACIONAL DE RESÍDUOS SÓLIDOS (PNRS) E A GESTÃO INTEGRADA DE RESÍDUOS NO MUNICÍPIO DE PARAGOMINAS}

No município de Paragominas, foi possível verificar-se, através das entrevistas, que a gestão integrada de resíduos sólidos é comumente confundia - por parte de alguns gestores de resíduos no município - com o gerenciamento de resíduos sólidos. "A gestão integrada de resíduos sólidos no município de Paragominas abrange o agrupamento de funcionários que realizam as atividades de coleta, transporte e destinação final dos resíduos", dizem os entrevistados A e C. Esta “confusão" de conceitos evidencia que os gestores municipais responsáveis pelos resíduos sólidos não possuem conhecimento avançado do conteúdo da PNRS.

O gerenciamento de resíduos sólidos, diferentemente da gestão integrada de resíduos sólidos, "consiste no conjunto de ações exercidas, direta ou indiretamente, nas etapas de coleta, transporte, transbordo tratamento e destinação final ambientalmente adequada dos resíduos sólidos e disposição final ambientalmente adequada dos rejeitos" (BRASIL, 2010).

No contexto da gestão de resíduos sólidos, o parágrafo primeiro do art. 18 da PNRS, enfatiza que, serão priorizados no acesso aos recursos da União, os municípios 

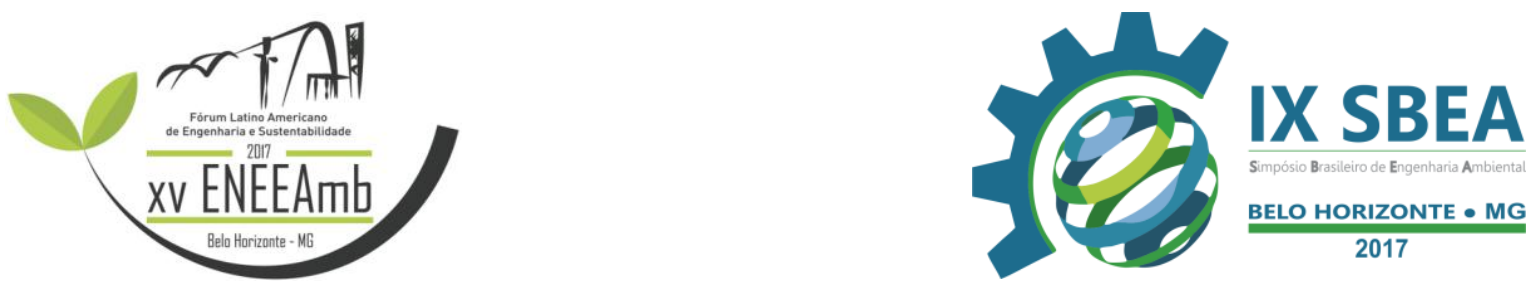

que desenvolverem diversas práticas relacionadas a gestão de resíduos sólidos, entre elas a implantação da coleta seletiva com a participação de cooperativas ou outras formas de associação de catadores de materiais reutilizáveis e recicláveis formadas por pessoas físicas de baixa renda.

O acesso aos recursos estabelecidos no art. 18 serão destinados aos municípios que possuírem uma população acima de 50 mil habitantes, afirma o entrevistado A. O mesmo destaca que o município de Paragominas ainda não apresenta a praticidade da coleta seletiva em razão das dificuldades de acesso aos recursos disponibilizados pelo Plano Nacional de Resíduos Sólidos. Entretanto, o município já obteve a aprovação de um programa de coleta seletiva na quarta Conferência Nacional de Resíduos Sólidos e Meio Ambiente, realizada em Brasília, no ano de 2014. "Este programa é baseado na Política Nacional de Resíduos Sólidos”, diz o entrevistado.

Todos os programas de coleta seletiva municipais são baseados no Plano Nacional de resíduos sólidos, pois não há como os municípios arcarem com todos os custos, haja vista que estes são bastantes elevados, enfatizou o entrevistado da secretaria de limpeza.

Apesar da evidência, por parte do entrevistado da secretaria de limpeza, de que o município possui um Programa de Coleta Seletiva aprovado pelo Governo Federal, este está bem distante de entrar em prática, diz o entrevistado. Esta falta de data para praticidade do programa, demonstra a constante necessidade por parte dos municípios, da liberação de recursos da União para o desenvolvimento de programas ligados a Políticas Públicas, tais como Saneamento.

\subsection{IMPORTÂNCIA DOS CATADORES DE RESÍDUOS NA GESTÃO} INTEGRADA DE RESÍDUOS SÓLIDOS NOS MUNICÍPIOS

A Política Nacional de Resíduos Sólidos estabelece no Art. 41 que os planos municipais de gestão integrada de resíduos sólidos definirão programas e ações para a participação dos grupos interessados, em especial das cooperativas ou outras formas de 

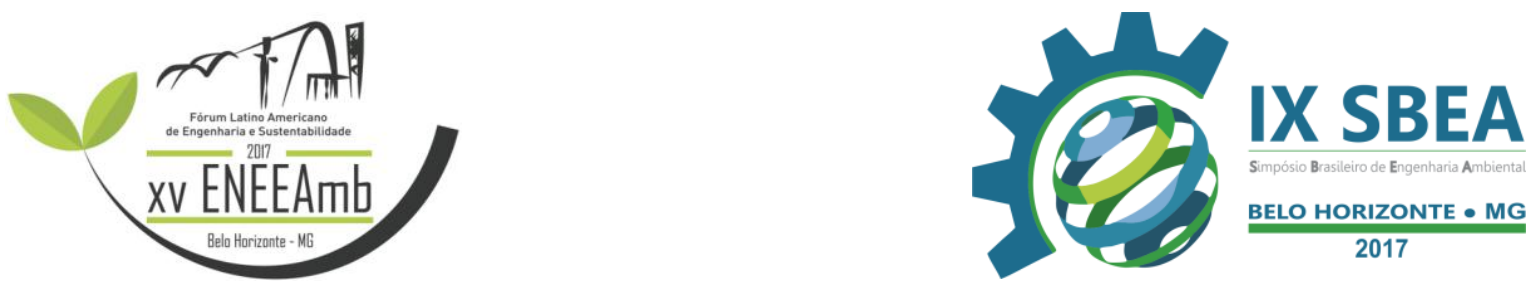

associação de catadores de materiais reutilizáveis e recicláveis formadas por pessoas físicas de baixa renda.

Apesar do município não desenvolver uma gestão integrada de resíduos sólidos, o mesmo conta atualmente com duas cooperativas de resíduos sólidos, uma de resíduos secos, denominada COOPERCAMARI localizada na área do aterro controlado, formada por 27 catadores e outra de resíduos orgânicos no condomínio Morada dos Ventos, denominada COOMPAG.

A cooperativa localizada no aterro controlado, de acordo com os entrevistados A e B, não recebem recursos diretos da prefeitura. Esta contribuiu no processo de instalação da cooperativa e realizou a compra dos equipamentos utilizados para a realização das atividades de separação dos resíduos, tais como prensa e esteira

Os integrantes das cooperativas deixam claro, que há a necessidade de participação mais direta da Prefeitura nas atividades desenvolvidas por eles. "Nós precisamos de um transporte para levar não todos, mas tem umas senhoras que não tem como ir de bicicleta e pra ir a pés é muito longe. Se eles ajudasse sobre isso já era uma importância, já era muito bom", diz o membro da cooperativa COOPERCAMARI. Esta declaração remete à necessidade do desenvolvimento de programas e ações, por parte do poder público municipal, voltadas para a participação de grupos de catadores de forma compensatória a ambos os lados.

\section{RESÍDUOS}

\subsection{PLANO DIRETOR DE PARAGOMINAS E A GESTÃO INTEGRADA DE}

Vários pontos relacionados à gestão de resíduos sólidos são apontados no Plano Diretor do município de Paragominas no art. 67, entre eles, a coleta seletiva, o tratamento de resíduos, campanhas educativas e monitoramento da vida útil do aterro sanitário, itens “e”, "h"," j" e "k", respectivamente. A coleta seletiva, especificada no Plano Diretor, no item "e", já foi esplanada neste trabalho.

Outra questão a ser considerada, é o tratamento de resíduos, estabelecido no item "h" do Plano Diretor. O tratamento deverá ser realizado em "complementação ás 

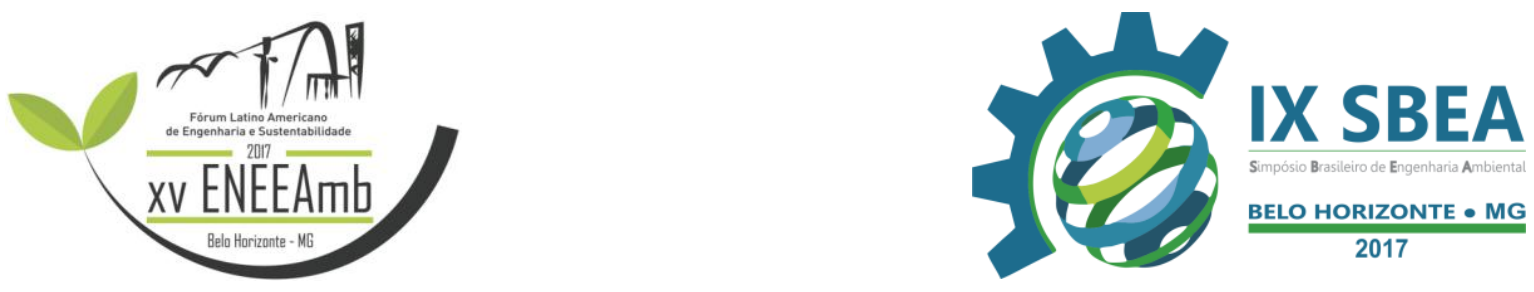

operações de destinação final do aterro sanitário conscientes sobre o impacto desses rejeitos no solo, na água e no ar ao longo dos anos" (PARAGOMINAS, 2016). Os entrevistados $\mathrm{A}$ e $\mathrm{C}$ enfatizam que "a única forma de tratamento dada aos resíduos é a coleta realizada pelos catadores na cooperativa COOPERCAMARI e a compostagem, realizada na cooperativa COOMPAG”.

A "única forma de tratamento" apontada pelos entrevistados anteriormente, é a separação que os catadores realizam nas cooperativas. Tais formas, poderiam ser melhor efetivadas se o município auxiliasse de forma direta as cooperativas existentes no território municipal. Este fato é consequência da ausência de um programa de coleta seletiva em execução. A falta da praticidade da coleta seletiva provoca o desperdício de muitos materiais que poderiam ser reciclados, reutilizados ou até mesmo reintegrados.

A ausência de alternativas de tratamento dos resíduos no município, pode ser verificada de forma mais clara, quando analisamos a quantidade de resíduos produzidos diariamente, a quantidade que é separada pelas cooperativas e a quantidade que é disposta no aterro controlado. A produção de resíduos no município de Paragominas, diariamente, de acordo com o entrevistado "A", chega a 58 toneladas. Entretanto, apenas $42 \%$ é devidamente separado. O restante dos resíduos produzidos é depositado em células, no aterro controlado.

A coleta de resíduos não é realizada em todo território do município. Nas zonas mais afastadas, como a colônia "onça", a coleta não é efetivada, em razão da quantidade mínima de resíduos produzidos. Porém, os moradores são instruídos por palestras da prefeitura para realizarem o processo de compostagem com os resíduos orgânicos, afirma o entrevista " $A$ ".

Outro item destacado no art. 67 do Plano Diretor, é a realização de "campanhas educativas com a utilização de cartilhas, folders, na imprensa (jornal, rádio e tv), entre outros, para despertar a consciência do cidadão sobre a questão do lixo na cidade" (PARAGOMINAS, 2016). O entrevistado "A" declara que a prefeitura realiza campanhas 

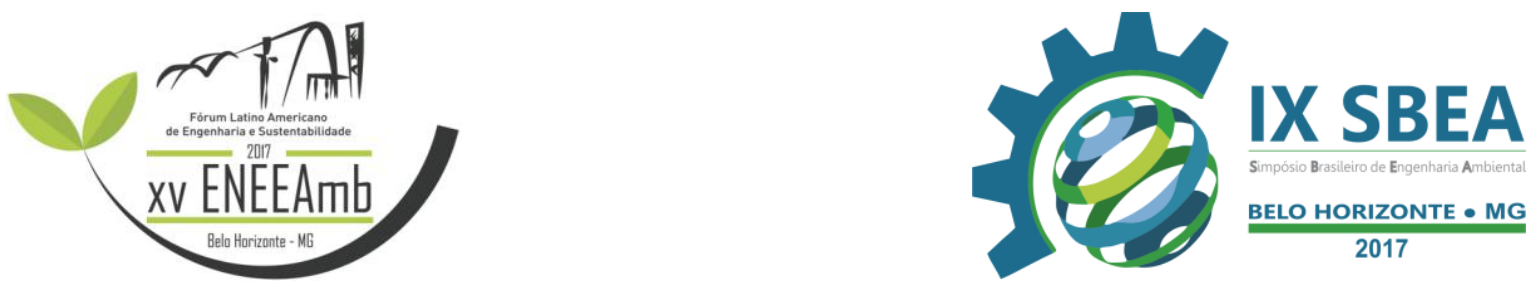

de conscientização dos moradores nas comunidades e nas escolas, sobre a importância da separação de resíduos e da destinação correta dos mesmos.

A ausência de um programa de coleta seletiva, mais uma vez deve ser ressaltado, pois juntamente com este, as campanhas educativas nas escolas e nas comunidades teriam efeito maior. A população não se compromete na separação dos resíduos em casa, justamente pela ausência da praticidade da coleta seletiva. Alegam que as sacolas contendo os resíduos são destruídas no carro coletor. Entretanto, o entrevistado da secretaria de limpeza afirma que, já foram realizados inúmeros testes de compactação das sacolas no carro coletor, e estas não são destruídas.

Outro item importante que merece destaque no art. 67 do Plano Diretor, é o item "k", que está relacionado à vida útil do aterro sanitário e da destinação final do chorume para evitar a contaminação do solo e subsolo. $\mathrm{O}$ entrevistado " $\mathrm{C}$ " declara que o aterro controlado do município tem prazo de validade até dezembro de 2017, ou seja, a prefeitura necessita elaborar um novo projeto de aterro sanitário para a disposição final dos resíduos produzidos.

Em relação ao chorume produzido durante a decomposição dos resíduos no aterro, este é encaminhado através de uma tubulação, por gravidade, até o poço de chorume. "Após atingir certo nível, o chorume é drenado e levado por caminhões-pipas até a Estação de Tratamento de Esgotos Morada do Sol", afirma o entrevistado "C". Na ausência de uma destinação adequada, o chorume pode infiltrar no solo e contaminar o lençol freático do local.

\section{CONCLUSÕES}

De acordo com a análise efetivada por meio de entrevistas com atores sociais ligados à gestão de resíduos sólidos no município de Paragominas e no estudo das Legislações pertinentes à gestão integrada de resíduos sólidos, verificou-se que o município desempenha uma gestão que não está em consonância total com a Política Nacional de Resíduos Sólidos e nem com os itens especificados no art. 67 do Plano 

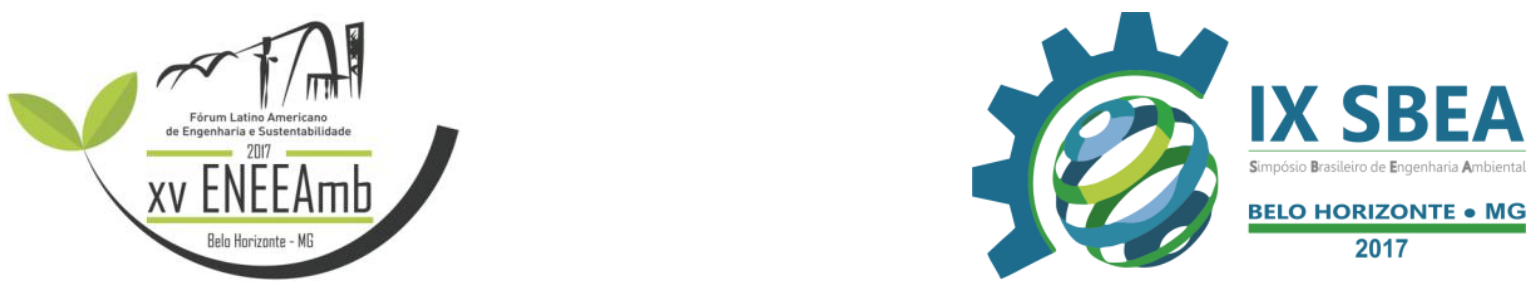

Diretor do Município. Estes fatos indicam de forma direta, que o município não desempenha uma gestão integrada de resíduos sólidos.

É necessário o desenvolvimento de Políticas Públicas municipais voltadas para a integração das concepções sociais, econômicas, ambientais e culturais na gestão de resíduos sólidos, permitindo dessa forma a execução de uma gestão integrada. Ainda é necessário a consideração dos itens estabelecidos no Plano Diretor que devem ser observados nos planos e projetos da política municipal de infraestrutura relacionada à Limpeza Urbana.

\section{REFERÊNCIAS BIBLIOGRÁFICAS}

BRASIL. Lei $\mathrm{n}^{\circ}$ 12.305, de 2 de agosto de 2010. Institui a Política Nacional de Resíduos Sólidos; altera a Lei no 9.605, de 12 de fevereiro de 1998; e dá outras providências. Presidência da República Casa Civil: Subchefia para Assuntos Jurídicos. Brasília, 2 ago. 2010.

GÓES, Helivia Costa. Coleta seletiva, planejamento municipal e a gestão de resíduos sólidos urbanos em Macapá/AP. Planeta Amazônia: Revista Internacional de Direito Ambiental e Políticas Públicas, Macapá, v. 3, n. 2, p.45-60, fev. 2011. Disponível em: <file:///C:/Users/Karine Lima/Downloads/461-2031-2-PB.pdf>. Acesso em: 28 set. 2016.

MESQUITA, J. M.de J. Gestão integrada de resíduos sólidos. Coordenação de Karin Segala. - Rio de Janeiro: IBAM, 2007. 40 p.

NBR, ABNT. 10004:2004. Resíduos Sólidos: Classificação. Rio de janeiro: ABNT, 2004.

PARAGOMINAS. Lei n 765 de 2011. Institui o Código Ambiental Municipal - CAM, contendo a Política e o Sistema Municipal de Meio Ambiente de Paragominas e dá outras providências. Câmara Municipal de Paragominas.

PARAGOMINAS. Lei n 597 , de 4 de outubro de 2006. Institui o Plano Diretor de Desenvolvimento Urbano do município de Paragominas e dá outras providências. Prefeitura Municipal de Paragominas. 

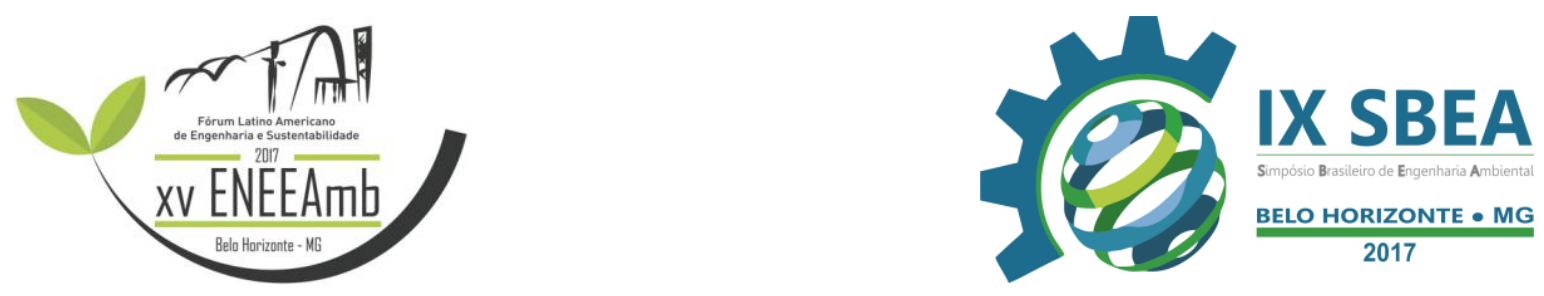

PEREIRA, J.T.N. Gerenciamento do Lixo Urbano: Aspectos Técnicos e Operacionais. Viçosa: UFV, 2006. 163 p.

PNRS. Plano Nacional de Resíduos Sólidos. Brasília. 2012. Ministério Do Meio Ambiente. Disponível em:< http://www.mma.gov.br/pol\%C3\%ADtica-deres\%C3\%ADduos-s\%C3\%B3lidos>. Acesso em: 28 set. 2016.

SCHNEIDER, V.T. Plano de Gerenciamento de Resíduos de Saúde do HUBFS. Belém, 2009. Disponível em:https://intranet.univates.br/tecnicos/media/artigos/Vanessa_Scheneider.pdf.Acesso em: 25 ago. 2016. 